\title{
Enunciación
}

http://revistas.udistrital.edu.co/ojs/index.php/enunc

\section{Seminario Taller Creativo, Danza. Historias de vida en el hacer de una maestra}

\author{
Creative Seminar-Workshop, Dance. Stories of life in a teacher's work \\ Martha Cecilia Palacios Manyoma ${ }^{1}$
}

Para citar este artículo: Palacios, M. C. (2015). Seminario Taller Creativo, Danza. Historias de vida en el hacer de una maestra. Enunciación, 20(1), pp. 109-118.

Recibido: 15-abril-2015 / Aprobado: 20-junio-2015

\section{Resumen}

A partir de su historia de vida (microhistoria) la maestra busca encontrar las raíces de sus prácticas docentes con la danza en la formación de maestros en la Escuela Normal Superior Distrital María Montessori, para reflexionar sobre ellas y enriquecerlas. La mueve una constante inquietud por saber de dónde viene su interés por la historia de los cuerpos, de las corporeidades y la subjetividad que los constituyen. En esta búsqueda centra su atención en las huellas de lo aprendido en el espacio de su hogar y en otros espacios de su vida para reflexionar cómo estos encuentros marcaron su cuerpo-corporeidad. Plantea una ruta de trabajo con la danza y la corporeidad que también tenga en cuenta a los estudiantes como sujetos con una historia y unas posibilidades expresivas propias.

Palabras clave: danza, corporeidad, expresión, historia y formación.

\begin{abstract}
Based on her life story (micro-story), the teacher seeks to find the roots of her teaching practices with the dance in the teacher training at Escuela Normal Superior Distrital Maria Montessori, to reflect on and enrich them. She is moved by a constant concern to know where her interest in the story of bodies, the corporealities and subjectivity that constitutes them comes from. In this search, she focuses her attention on the traces of what she learned in the space of her home and in other areas of her life to reflect on how these meetings marked her body-corporeality. She outlines a roadmap with both dance and corporeality which also considers the students as subjects with a story and their own expressive possibilities.
\end{abstract}

Keywords: dance, corporeality, expression, story and training.

1 Magíster en Educación Artística de la Universidad Nacional de Colombia, especialista en Infancia, Cultura y Desarrollo, Universidad Distrital Francisco José de Caldas. Maestra del programa de formación complementaria Escuela Normal Superior Distrital María Montessori. Correos electrónicos: normalmariamontessori@gmail.com, mcpalaciosmanyoma@gmail.com 


\section{INTRODUCCIÓN}

Con este trabajo deseo comunicar a otros maestros aquellos saberes que he construido desde el área de Educación Artística, pues es desde mi práctica con la danza donde surge la necesidad de compartir mi experiencia como formadora de normalistas superiores (título académico que otorga la Escuela Normal Superior Distrital María Montessori - Bogotá [ENSDMM]) a los maestros en formación), asumiendo una postura política desde la convicción de aquella maestra que ve la vida como un espiral girando en busca de una construcción colectiva, al encuentro de un acto expresivo que permita a sus estudiantes encontrarse con ellos mismos como sujetos críticos para crear y explorar su corporeidad con los otros a través de la danza, puesto que danzar implica detener la mirada frente a lo observado e hilar finamente las percepciones y sensaciones de cada sujeto. La danza aparece en el escenario poseída por el cuerpo del bailarín que goza y se mueve al ritmo de los sonidos musicales. El cuerpo es tomado en su autonomía total, en su expresión y sensibilidad; visto así, se convierte en una alternativa pedagógica de transformación.

Desde esta mirada se concibe que la percepción o conciencia del propio movimiento estimula la autoconfianza y la flexibilidad, lo que proporciona una mayor capacidad para manejar situaciones nuevas y solucionar problemas. La liberación de los movimientos corporales estimula el proceso intelectual y la capacidad creativa.

A lo largo de la historia podemos constatar que el control que se ejerce sobre el cuerpo muestra sus resultados en relaciones de docilidad - utilidad. Cuanto más obediente se muestra el cuerpo a las órdenes que vienen desde el exterior, más útil y más controlable es el ser humano. Se desarrolla así una "política de la coerción" que actúa sobre el cuerpo manipulando sus gestos y comportamientos. Podemos decir que se da origen a una "anatomía política" que, como tantas otras formas de control y represión, es un "mecanismo del poder" (Ostrower, 1977).
Es importante entender entonces la relevancia de la actitud corporal, ya sea para la reproducción del orden social, o como un acto emancipador, para la autocomprensión y desarrollo del sujeto. Optar por la búsqueda de nuevos caminos no es tan sencillo en medio de tantas presiones y desconocimientos frente al lenguaje de la danza. Sin embargo, a quienes estamos inmersos en el tema educativo nos corresponde continuar investigando sobre aquel cuerpo que dice y se resiste a recibir órdenes que aquietan la posibilidad de pensar.

La búsqueda del propio danzar es un acto de resistencia frente a la homogenización impuesta por la industria cultural que determina imágenes-movimiento estereotipados y construye una corporeidad que niega la historia cultural y personal del danzante.

La propuesta para la formación de un maestro que desea afrontar la corporeidad desde la danza se puede abordar desde la perspectiva de Rico (2012), quien plantea dos abordajes: desde lo biológico —el cuerpo que se tiene-, y desde aquel cuerpo construido a través de la experiencia de cada cual en el contexto cultural en que ha crecido - el cuerpo que se es-. A partir de este enunciado, el cuerpo es producto de la historia; está hecho del acervo cultural de los ancestros, es el fruto de un país y una época, y de manera más fina es el producto de un territorio con unas características sociales y geográficas particulares. Sin embargo, como cuerpo histórico se transforma según las nuevas experiencias, reflexiones y contextos que experimenta.

En la corporeidad vista desde la danza, cada cuerpo se piensa de manera diferente: como creador de su propia voz en la medida en que cobra conciencia de sí y de los otros en un espacio histórico y cultural. La educación artística en la escuela posibilita pensar otras perspectivas en las cuales no se reducen los sujetos solo al saber, sino que son pensados en su complejidad. La educación artística orientada desde la danza posibilita que el maestro reconozca la importancia de su cuerpo y su particularidad en relación con los otros. 
Cuando en el danzar los movimientos y las sensaciones son actos conscientes, se despierta el reconocimiento propio. En ese despertar suceden tres actos de manera simultánea: se reconoce a sí mismo en sus potencialidades y limitaciones; se diferencia de los otros desde sus capacidades; y, por último, se apropia de unos saberes desde sus necesidades (Nussbaum, 2012). Cada sujeto en un encuentro dancístico busca horizontes desde los cuales crear una voz como sujeto para dialogar con otros desde su cuerpo.

\section{METODOLOGÍA}

Ahora bien, ¿qué camino seguir para la construcción de una corporeidad en la formación de maestros en la ENSDMM que tenga en cuenta los planteamientos anteriores?

Inicialmente y desde un enfoque cualitativo, esta propuesta es abordada desde la metodología de la microhistoria ${ }^{2}$ (que es a su vez un planteamiento de la línea de investigación Otra hoja de ruta para la educación artística, de la Maestría en Educación Artística de la Universidad Nacional de Colombia). La microhistoria es una metodología de investigación que permite a través de la narración visibilizar lo que parece obvio.

Tomé conciencia de concepciones y prácticas de trabajo con mis estudiantes tras indagar los elementos que constituyen la historia de mi propia corporeidad y también replantear conceptos y enriquecer acciones pedagógicas para el maestro en formación desde la danza.

\section{AL ENCUENTRO DE MI CORPOREIDAD}

Desde la microhistoria es posible indagar acerca de esos espacios donde fuimos cuerpo y qué elementos de nuestra historia colectiva y personal se

2 El enfoque microhistórico aborda el problema de cómo acceder al conocimiento del pasado mediante diversos indicios, signos y síntomas. Es un procedimiento que toma lo particular como punto de partida (particular que es a menudo altamente específico e individual y sería imposible calificarse como caso típico) y procede a identificar su significado a la luz de su contexto específico. reflejan en nuestras corporeidades actuales, entendida esta en la relación con los demás, con los espacios y con los objetos en los diferentes contextos que nos atraviesan: la familia, la escuela y el barrio, a través del cuerpo en una relación compleja: somos cuerpo y de la misma manera nuestro cuerpo es lo que somos (Rico, 2012). En esta estrecha relación hemos dejado de escuchar los sonidos y susurros de nuestra piel y su memoria para doblegarnos hacia los discursos que predominan en donde la voz del maestro (su corporeidad) está ausente. Es necesario entonces, para romper este cerco, abrirse hacia otros discursos que propicien la reflexión y permitan tanto en el maestro como en los estudiantes opciones diferentes para abordar su cuerpo (Pedraza, 2011).

\section{HOGAR: UN CUERPO DE RESISTENCIA EN MOVIMIENTO}

Comienzo por mirarme como una mujer en resistencia que se mueve haciendo un reconocimiento de sus ancestros y de la conservación de unas prácticas y rituales de mis raíces africanas, puesto que ellas están mucho más cerca de mi construcción de mujer como maestra afrocolombiana (nací en Bogotá, me crié en Medellín, y mis padres eran chocoanos).

En mi hogar, el cuerpo fue tratado de manera cuidadosa y con mucho respeto. Existían como herencia de mis abuelos chocoanos rituales alrededor de su cuidado. A los niños recién nacidos se les hacía un rezo para protegerlos de cualquier daño. Toda nuestra familia era purgada una vez al año y se hacían ayunos de limpieza de manera periódica. El cuerpo en movimiento estaba presente en todas las celebraciones sociales, familiares y religiosas. Se bailaba y todos lo hacíamos.

Las hijas en el hogar aprendimos directamente de nuestros dos padres a jugar y danzar siguiendo el impulso del ritmo y la expresión natural. La enseñanza, como lo describe García (2007), tenía su centro en el hogar, y así mismo la formación de hábitos y valores. En mi familia tuve la oportunidad 
de ser yo misma en un ambiente que si bien no estaba exento de conflictos, primaba el amor en la aceptación de la diferencia, en el abrazo y la complicidad de la mirada.

La oralidad se presentaba en el cuerpo de mi madre cuando en los refranes nos dejaba algo que aprender sobre la naturaleza, o en el caso de mi padre con sus narraciones de lo que le sucedía cuando sembraban arroz en La Troje (corregimiento de Quibdó, Chocó), o cuando él participaba tocando la marímbula en las valsadas por el río Atrato (a la manera de las carrozas terrestres de carnavales como el de Pasto), actividad de tradición en las fiestas de San Pacho.

Llego a Bogotá a hacerme maestra en la ENSDMM (institución formadora de maestros). De seguro esta elección tiene relación con el hecho de que a mi casa llegaban muchas chocoanas que eran maestras y hablaban tan bonito de su profesión que eso me hizo enamorar de lo que hago hoy. Sin embargo, tiempo después de iniciar mi oficio docente me sigo preguntando: ¿cómo es que llego a los otros? ¿Cómo es que en ellos se queda algo? Y entonces empieza mi memoria corporal a recordar en imágenes los espacios en movimiento de mi niñez.

Cuando recuerdo cómo aprendí a bailar, de inmediato se hace presente la imagen de mis progenitores, pues ambos incidieron en este sentir. Mi padre nos reunía a sus tres hijas en el patio de la casa y jugaba todo el tiempo con nosotras; nos contaba sobre los ritmos chocoanos (el abozao, el pichinde, el carpintero), bailábamos y debíamos pasar por debajo de un palo inclinando la espalda hacia atrás y otras maromas más ${ }^{3}$.

Realmente era muy divertido. De igual manera, recuerdo las tardes de un sábado o un domingo cuando nos reuníamos todos en la sala: mi papá ponía música en la radiola para bailar (salsa,

3 Juegos tradicionales del Chocó en donde se hace formación musical y corporal de una manera natural y cotidiana fuera del espacio escolar.

4 Ángel Viloria integrante del Conjunto Típico Cibaeño, región de República Dominicana, intérprete del acordeón en el ritmo del merengue. vallenato, porros, merengues de Ángel Viloria ${ }^{4}$ ) y, como éramos tres mujeres, entre nosotras bailábamos y los viejos también. Papá sólo nos decía que le cogiéramos el golpe a la música (manera de sentir el ritmo y expresarlo de forma natural con el cuerpo). No recuerdo que ellos nos pusieran a imitar su forma de moverse. Yo aprendí a conocer mi cuerpo en su interioridad y exterioridad de esa manera: escuchando los sonidos de la música con otros. Es desde esta experiencia de mi infancia que en mis prácticas busco que los estudiantes se expresen de manera natural, es decir, desde su historia y sus posibilidades buscando su propio "golpe".

De otro lado, crecí en un lugar (Medellín) en donde fue necesario afirmarnos como familia y hacer resistencia de nuestra cultura afro en el espacio de la fiesta para el encuentro con los otros. Con el tiempo mi casa llegó a ser muy visitada por el cura del barrio, la rectora del colegio, las profesoras de la escuela en la que hice la primaria y por los chocoanos amigos y familiares. Tanta diversidad me permitió relacionarme con personas que deseaban ser ellas mismas a pesar de las circunstancias, y presenciar cómo las festividades convocaban el hablar y el existir en el barrio Girardot (ubicado al noroccidente de Medellín).

El sonido de clarinete, el bombardino y los platillos reunían al barrio en torno a la aceptación de una cultura diferente ${ }^{5}$ a la de ellos, y qué decir de la sabrosura del sancocho que a media noche detenía la música para deleitar esos sabores traídos de Quibdó.

\section{Un cuerpo en la escuela}

Para la misma época viví otras experiencias corporales en la escuela pública en la que estudié la primaria. El espacio del salón se organizaba de una manera particular: los pupitres se compartían,

5 "La polka, la contradanza, y la danza llegaron de Europa; venían maestros que ensañaban estos bailes de salón. Pero la gente de la servidumbre, tanto en el chocó como aquí en Bogotá veían bailar esa gente. Para el Chocó y otros asentamientos de afros con esta relación se dio un mestizaje de estas formas de danza: de origen europeo, pero con rítmicas y movimientos corporales afro" (Entrevista al maestro Alberto Londoño, septiembre 25 de 2013). 
siempre se tenía una compañera al lado, ya que solo estudiábamos niñas. El salón estaba organizado en cuatro filas.

La competencia entre nosotras se medía a través de resultados (las calificaciones) y se materializaban en el afecto o rechazo de la maestra. Ella, de acuerdo con nuestro rendimiento académico, nos ubicaba dependiendo de las materias perdidas. Quien no perdía ninguna se sentaba en la primera fila de los pupitres muy cerca a la imagen religiosa que se encontraba ubicaba en la parte superior del tablero; pero las que no pasaban alguna materia eran ubicadas en las filas dos, tres y cuatro. En particular, por las materias que Ilevaba perdidas me correspondía casi siempre la última fila al lado de la ventana que daba al corredor (Escuela Sor Juana Inés de la Cruz, Medellín, 1971).

Para mantener el orden y obtener resultados la enseñanza lancasteriana o monitorial, recurría a los premios por los logros y castigos al error:

Los primeros eran otorgados a los estudiantes que mostraban excelente comportamiento y desempeño durante las clases y los certámenes públicos. Entre los premios se encontraban sumas de dinero, textos escolares y utensilios de uso personal. Los castigos eran empleados para corregir las malas costumbres y defectos. Eran motivo de castigo el irrespeto al maestro, el vocabulario impúdico, faltas contra la moral y la decencia. Como métodos de corrección se usó el causar dolor físico como palmetazos, azotes, férulas o también encierros para realizar alguna tarea bajo vigilancia o la utilización de gorros con letreros vergonzosos de acuerdo a la falta cometida (perezoso, distraído, burro, puerco), privación de vacaciones, reprensiones con los compañeros de testigos, todo ello con el fin de formar hábitos (Parra, 2007 , p. 10).

El único que podía hablar era el maestro; las estudiantes lo hacíamos solo cuando se leía en voz alta o cuando la maestra preguntaba. El ambiente era de total quietud y de un silencio impuesto agresivamente para una niña de apenas ocho años. No era la participación y la posibilidad de expresarse con libertad como había sucedido hasta ahora en mi casa. La obediencia era la nueva lección aprendida del modelo de la educación lancasteriana: no contestar a los mayores y aceptar castigos del maestro (todo era hecho por el bien del estudiante) ${ }^{6}$. Fue así como no pude participar del grupo de danzas de la institución como resultado de mis malas notas: una actividad muy importante para mí y que había realizado hasta el momento con mucha libertad se convertía ahora en un mecanismo de control, un cuerpo negado.

Situaciones como las que he contado más arriba, de señalamiento y discriminación que me sucedieron, fueron comunes en la historia de la educación de este país; desde ahí es posible hablar de la construcción de una corporeidad relacionada con la obediencia y la sumisión.

Más adelante, luego de terminar el grado once, tuve la posibilidad de estudiar en la Escuela Popular de Arte (EPA), ubicada en el barrio La Floresta, de Medellín, la carrera de danzas folclóricas (1983). Si bien no sabía la razón que me impulsaba, pues no tenía en ese momento conciencia de mi corporeidad, decidí continuar estudiando al superar el dolor de la quietud del cuerpo impuesta por la educación escolar que ya relaté, caracterizada por la exclusión, la negación y la burla; lo hice como una forma de revelarme buscando otras maneras de decir en este nuevo espacio que era más acorde con lo vivido en el seno familiar.

Al llegar a la EPA me encuentro con otro sitio donde se puede hacer resistencia (el primero fue el de mi familia), pues allí se hace un reconocimiento al cuerpo desde el territorio, desde la identidad ancestral. Con el maestro Jesús Mejía aprendí a hacer las primeras cartografías del

6 El castigo fue una herramienta de gobierno y coadyuvó a la crianza de los sujetos escolarizados y a la educación de la juventud, tanto en los Estados Unidos de Colombia como en el Estado Soberano de Antioquia (Ossa, 2010). 
folclor colombiano, a conocer su organología (clasificación de los instrumentos por división político-geográfica) y la bromatología (historia de los alimentos propios de cada región). Con el maestro Alberto Londoño continúo la búsqueda de ese cuerpo que se podía expresar de una manera relacionada con su propia realidad en la oralidad y en los sonidos producidos en las regiones del territorio colombiano. Cuando él iniciaba contándonos la historia de cada ritmo que se baila, me permitía pensar que desde allí la corporeidad se manifestaba de otras maneras, con más apropiación; con él exploré lo que es la planimetría coreográfica.

Más adelante, estando en la misma institución, hago parte del grupo coreo-musical Los canchimalos (un pez pequeño que al ser tragado por uno más grande se lo puede comer todo por dentro y salir vivo). Y con el maestro Oscar Vahos (director del grupo) se amplía la posibilidad de hacer presencia en otros escenarios, de ser vista y reconocida como una bailarina que expresaba algo desde lo individual pero en colectivo; junto a él logramos representar las formas como en cada región del país se jugaba; así, recorrer los barrios populares de Medellín jugando nos dejaba una idea de estar haciendo presencia ante los otros desde el goce, en el disfrute de hacer resistencia a la adversidad producida por la carencia de políticas que favorecieran a algunos sectores de la cuidad.

Entre mi experiencia familiar y la de la EPA encuentro puntos de conexión con lo que actualmente estoy haciendo en mi práctica docente. Uno de ellos es una proximidad amorosa y espontánea con la música y con la danza. Igualmente, en ambos espacios de mi experiencia danzante, las músicas tradicionales colombianas y latinoamericanas fueron de gran importancia. Hoy estas expresiones ancestrales son materia de trabajo en mis clases, por ejemplo en el Seminario taller creativo: danza.
De otro lado, en mi casa - a través de la invitación de mi padre a "coger el golpe" de la música y llevarlo al cuerpo - pude experimentar una didáctica popular de gran riqueza en donde el desarrollo musical y corporal está ligado directamente al juego. Tomar conciencia de esta circunstancia privilegiada de mi historia personal da cuenta del origen de la preocupación que he mantenido a lo largo de mis años como docente de danza por que los chicos encuentren su propia corporeidad, es decir su propio golpe en un cuerpo con historia. Es desde el conocimiento puesto en la palabra escrita que es posible pensar el papel de la formación como un acto en el que nos construimos como sujetos de saber gracias a un movimiento en espiral en donde no hay un adelante y un atrás para apuntar a la construcción de colectividades diversas (Arendt, 1997) $)^{7}$.

\section{PENSAR LA CORPOREIDAD EN LA FORMACIÓN DE MAESTROS EN LA ENSDMM}

El cuerpo es el espacio donde todo se instala o se transforma, lugar de vida y muerte, posibilidad de construcción para poder estar con los otros.

Frente a una relación coercitiva del cuerpo del estudiante, abogo por una propuesta que involucre la danza y el cuerpo, orientada más hacia el autorreconocimiento y la libertad. Esta postura ha precisado en primera instancia reafirmar a través de la microhistoria la maestra inquieta que se resiste a ignorar lo que le afecta y la limita; la que busca nuevas construcciones estudiando y dejándose permear por otros discursos pedagógicos y artísticos para desde ahí enriquecer una práctica que le apuesta a una construcción en colectivo, donde esté presente la experiencia de vida de cada sujeto para ir creando nuevas formas de sentir, pensar y danzar.

La condición indispensable de la política es la irreductible pluralidad que queda expresada en el hecho de que somos alguien y no algo 
En este sentido, la clase se puede realizar en un ambiente de exploración con muchas posibilidades en donde la escritura, el cine, el encuentro con otros (salidas a espacios académicos y artísticos), el encuentro con la imagen y la conversación apunten hacia la construcción de una corporeidad en un espacio de expresión como un acto holístico e interdisciplinar.

Entonces, un estudiante del programa de formación complementaria que realice la práctica pedagógica en los niveles de preescolar y primaria está abocado a asumir un trabajo que le permita:

- La experimentación, disposición corporal. En el espacio de la danza es forzosa la posibilidad de explorar el propio cuerpo en el disfrute del mismo. Solo a través de la experimentación se ofrece la oportunidad de percibir y gozar el movimiento que origina cada cual para generar procesos en otros cuerpos. Explorar desde las imágenes sonoras, la palabra, el tacto, el gusto, la vista y el juego.

- El encuentro con otras voces, rutas. Plantear salidas y encuentros con instituciones (proyecto Viajes, Rutas y Expediciones; cf. Manosalva, Palacios y Gutiérrez, 2010); propiciar la presencia de los estudiantes en escenarios públicos y privados donde es visible lo artístico. Este tipo de encuentros le permiten al maestro en formación lograr una percepción crítica como espectador; y por consiguiente alimentar sus prácticas y propuestas pedagógicas.

- La reflexión, conceptualización. Leer, escribir, preguntar, indagar y conversar son algunas de las acciones que ofrece el seminario-taller de la danza, con el objeto de propiciar otras imágenes desde el cuerpo del bailarín-maestro que lo inviten a abordar propuestas escritas, a hablar acerca de sus aportes y ver su pertinencia en la formación del normalista superior.

- La creación, montaje, puesta en escena. El acto de creación en el lenguaje de la danza supone un pensamiento flexible y juguetón que plantea otras formas de expresar, para vivir la coreografía como un acto de comunicar danzando. El acto creativo consolida la confianza y abre caminos para crear otras acciones que aborden el cuerpo en el espacio de la escuela, dejando volar la imaginación como muestra de un pensamiento crítico y sensible para romper con movimientos estereotipados.

Si bien me he referido a las acciones para lograr la expresión de la corporeidad, a continuación presento las estrategias que dispongo en el espacio académico, y luego ilustro esta metodología con un ejemplo.

\section{Estrategias metodológicas y actividades}

El espacio de trabajo de la propuesta del Seminario Taller Creativo, danza está dividido en dos momentos, el taller educativo y el seminario. Si bien se dan en espacios separados, se retroalimentan mutuamente.

El seminario: es un espacio de reflexión teórica a través de textos sobre la danza, su historia, el cuerpo, la creación, la relajación, la respiración. Se abordan también textos reflexivos desde la imagen: cine y documentales.

El taller educativo: en él se reconocen los movimientos básicos de locomoción. Se realizan ejercicios de sensopercepción, de coordinación y ritmo, de exploración espacial individual y grupal; de exploración de planos corporales, la exploración y creación de diseños coreográficos desde propuestas simétricas y asimétricas; el manejo de materiales; ejercicios de observar y ser observado. Se busca provocar la exposición frente a sí mismo y ante los demás. Ahora bien, las temáticas propuestas en el taller tienen que ver necesariamente con las historias de vida de cada joven (microhistoria-danzada), y son fragmentos de su existencia recogidos en algunos ejercicios de los cuales describiré brevemente cuatro.

- La silueta colgante: a partir de una silueta recortada de su cuerpo ubican las marcas (cicatrices) y reconstruyen momentos de la vida de cada cual que se socializan con los otros. 
- Le escribo a mi rostro: cada chico se observa en un espejo y a partir de un listado de preguntas se generan reflexiones sobre sí mismo (qué veo, a quién desearía parecerme, qué es lo que me gusta de lo que veo, qué cambiaría...). Igual, el resultado escrito se socializa con los otros y se lleva a escena en el taller educativo.

- Conversando en el bar: en un espacio preparado por ellos mismos se convierte el salón en un bar para conversar y leer. Se socializan las bitácoras y se cuentan otras historias de vida de cada chico. Se graba y se escribe un documento a partir de esta experiencia.

- La bitácora: en ella los chicos dejan consignado por escrito la evocación de lo vivido. Es un texto narrativo y reflexivo sobre las actividades realizadas en el taller, pero también sobre las lecturas, videos y materiales teóricos que se abordan en el seminario. En la bitácora cada estudiante (en primera persona) escribe sobre sus aprendizajes, sus sensaciones y preguntas.

\section{A manera de ejemplo, análisis de una actividad. Entre lo ácido y lo dulce}

Como en todas las actividades del taller que tienen que tienen que ver con la expresión danzada, iniciamos con ejercicios de estiramiento, rotación de segmentos corporales y expresiones gestuales.

La actividad es sugerida después de ver la película El Perfume en el espacio del seminario. El ejercicio consiste en que los estudiantes lleven un alimento ácido o dulce. Ya en el espacio de clase se ubican de manera individual con los materiales y cada cual prueba el sabor que llevó: debe buscar la manera de representarlo desde las evocaciones que le sugiere el sabor (su historia) a través de sus propios movimientos, ampliándolos hasta los límites de sus propias posibilidades expresivas. Lo socializa entre sus compañeros en el acto de observar y ser observado.

Luego en su bitácora debe registrar la sensación y darle un nombre a los movimientos construidos en el ejercicio. Presento a continuación un ejemplo.

Bitácora de Alejandra C., 7 de mayo del 2015. En esta clase la maestra nos pide realizar movimientos a partir de algo dulce y ácido.

Cuando probé lo ácido mis movimientos fueron un poco cerrados y no muy espontáneos. Se centraron en movimientos donde tanto los gestos y desplazamientos buscaban explicar lo que estaba sintiendo y de alguna manera poderlo relacionar. Lo hice con obstáculos, sufrimientos y cosas pasadas.

Al probar algo dulce mis movimientos fueron más alargados, sueltos. Mi rostro y mis movimientos reflejaban satisfacción y alegría.

El nombre que le di a este ejercicio fue vida, ya que con esta actividad pude relacionar la danza con momentos de mi existencia.

\section{Bitácora de la maestra}

La receptividad que se dio por parte de los estudiantes fue excepcional, estaban tan concentrados en su exploración de movimientos, que sentí mucha pena de interrumpirlos para continuar con la clase que tenía planeada. Me vi encerrada entre dos muros de tensión, pero deseando profundamente seguir con lo planeado. No fue posible, realmente ellos eran los protagonistas, no mi planeación, no la rutina que quería que siguieran. Entonces se me ocurrió en medio del temor y del rigor consultarlo con ellos, todos en coro contestaron: "Relajación".

Al finalizar la sesión se acerca Juan Carlos M. y me da las gracias por la clase. Expresa que para él fue un espacio muy importante. Siente que logró hacer cosas que no realiza en lo cotidiano: "Esa clase estuvo llena de nuevos y grandes aprendizajes"

La Tabla 1 resumen el conjunto de recursos empleados durante esta actividad. 
Tabla 1. Compendio de recursos metodológicos para una actividad

\begin{tabular}{|c|c|c|c|}
\hline Espacio & Ejercicio & Área & Emergencias \\
\hline Seminario & Ver película & Audiovisual-cine & $\begin{array}{l}\text { Propuesta exploración perceptiva corpo- } \\
\text { ral Olfato }\end{array}$ \\
\hline Taller Educativo & Danzar lo dulce y lo ácido & Danza & $\begin{array}{l}\text { Expresión de movimiento desde la pro- } \\
\text { pia historia, creación }\end{array}$ \\
\hline Taller Educativo & Observar y ser observado & Danza & $\begin{array}{l}\text { Comunicación. La construcción del sí } \\
\text { mismo en la relación con el otro }\end{array}$ \\
\hline Seminario & $\begin{array}{l}\text { Escritura del ejercicio } \\
\text { danzado }\end{array}$ & Lectura y escritura & $\begin{array}{l}\text { La descripción, la reflexión, la compren- } \\
\text { sión }\end{array}$ \\
\hline Seminario & $\begin{array}{l}\text { Conversación (Oralidad) } \\
\text { Conversando en el bar }\end{array}$ & Lectura y escritura & Socialización de las bitácoras. \\
\hline $\begin{array}{l}\text { Reflexión de la maestra en } \\
\text { ejercicio }\end{array}$ & $\begin{array}{l}\text { Observación y registro y } \\
\text { pedagogía }\end{array}$ & $\begin{array}{l}\text { Escritura } \\
\text { y pedagogía }\end{array}$ & $\begin{array}{l}\text { Reflexión, evaluación y enriquecimiento } \\
\text { de la práctica }\end{array}$ \\
\hline
\end{tabular}

Como se aprecia en la tabla, a través de la actividad se concretan dos intenciones y conceptos que se han expuesto en este artículo: se hace visible por un lado la relación entre diferentes áreas y, de otro lado, se ve el trabajo con la danza a partir de la historia de cada estudiante.

\section{ALGUNAS CONCLUSIONES}

Ubicar a los danzantes en espacios de sensaciones físicas y emocionales cercanas a sus vivencias e historias de vida les permite romper formas repetitivas de movimiento y crear posibilidades más próximas a ellos mismos y a sus universos expresivos; en ese sentido, la danza como lenguaje ofrece un encuentro con lo individual y lo colectivo.

De otro lado, aceptar los cambios en las corporeidades actuales de los jóvenes propone retos que exigen a los maestros dar los primeros pasos. La conciencia a través del movimiento y la danza pretende mostrar posibilidades para quienes están en la búsqueda de nuevos caminos en el desarrollo de una práctica pedagógica consciente y viable.

Actuar en consonancia con una propuesta que parta de la experiencias de vida de los estudiantes para configurar una corporeidad y un danzar propios permite a los maestros en formación un conocimiento de sí mismos para que ellos a su vez acepten a los otros(as) como sujetos de divergencia.

La invitación a tomar como materia prima del cuerpo para danzar (corporeidad) la historia personal (sucesos, emociones, experiencias, transformaciones) y la inevitable relación entre áreas que se alimentan mutuamente (interdisciplinariedad) son caminos y acciones que recorre una propuesta como la expuesta y deberían reflejarse necesariamente en las prácticas de los Maestros en Formación.

Un maestro que indaga sobre sí mismo y escribe sobre su quehacer como maestro a partir de su historia de vida toma conciencia de lo que lleva al aula de clase y la razón por la que lo hace.

\section{RECONOCIMIENTOS}

Este artículo de reflexión es producto del proyecto titulado Seminario Taller creativo, Danza. Historias de vida en el hacer de una maestra, de la Maestría de Educación Artística, de la Universidad Nacional de Colombia (enero de 2015), inscrito en la línea de investigación Otra hoja de ruta para la educación artística de la Facultad de Artes de la misma Universidad. 


\section{REFERENCIAS}

Arendt, H. (1997). ¿Qué es Política? Barcelona: Paidós.

García, B. (2007). De la educación doméstica a la educación pública en Colombia. Transición de la Colonia a la República. Bogotá: Universidad Francisco José de Caldas. Editoriales Universitarias de Colombia.

Manosalva, M., Palacios, M. y Gutiérrez, O. (2010). Viajes y Expediciones pedagógicas en la Escuela Normal Superior Distrital María Montessori. Experiencias de investigación y formación en contextos socio-culturales: urbanos, rurales, regionales y globales. Programa de Formación Complementaria. Bogotá: Imprenta Distrital.

Nussbaum, M. (2012). Crear capacidades: propuesta para el desarrollo humano. Barcelona: Paidós.
Ossa, A. F. (2010). El castigo como práctica de gobierno en la Reforma Instruccionista en Antioquia 1867. Revista Latinoamericana de Ciencias Sociales, Niñez y Juventud, 8(2), 1159-1168.

Ostrower, F. (1977). Creatividad y proceso artístico en niños. Rio de Janeiro: Editorial Vozes.

Parra, A. (2007). Método lancansteriano o enseñanza mutua en Colombia. Revista Edu-Física, Universidad del Tolima. ISSN 2027-453X

Pedraza G., Zandra. (2011). La educación del cuerpo y la vida privada. En J. Borja y P. Rodríguez (Dirs). Historia de la vida privada en Colombia. Tomo II. Los signos de la intimidad. El largo siglo XX (pp. 115-148). Bogotá: Taurus.

Rico, A. (2012). El cuerpo total, nuevo paradigma educativo. Construyendo inéditos viables. Primer Congreso Internacional de Educación, (pp. 1709-1722), México. 